\title{
Discurso pronunciado con motivo de la celebración del día de las Naciones Unidas, en Santiago el día 24 de octubre de 1980
}

\section{INTRODUGCYón}

Es un gran honor para mí haber sido invitado por el Secretario Ejecutivo de la cepal a tomar la palabra en la celebración del día de las Naciones Unidas en su sede de Santiago de Chile. Agradezco muy sinceramente esta muestra de estima. La atribuyo fundamentalmente a la larga y grata asociación que me ha correspondido mantener con los trabajos de CEPAL, prácticamente desde sus orígenes, y a mi vinculación también de largos años con el Comité de Planificación del Desarrollo de las Naciones Unidas, en el cual ha recaído la pesada responsabilidad de examinar los problemas del desarrollo mundial y recomendar las bases técnicas de las Estrategias Internacionales de Desarrollo.

En todo caso, siento mis insuficiencias al hablar en la sede de GEPAL, la Organización que con más ahínco e inteligencia ha trabajado en conocer y comprender los problemas de América Latina. Sólo pretendo añadir unos apuntęs de personal experiencia a la íntima identificación con que aquí se vive ese tema, cuya complejidad siempre dejará en la penumbra alguna "terra ignota" a la que es menester llegar.

Personalmente, creo que he seguido de cerca alrededor de tres décadas de la evolución económica de América Latina. Primero como planificador nacional; luego empeñado en el análisis de políticas de coyuntura en organismos internacionales, posteriormente inmerso en la tarea y en la pasión de la integración, y ahora como responsable de la política de comercio exterior e industrialización del Gobierno del Ecuador.

Sin ser parte de la Secretaría de ningún organismo de las Naciones Unidas, puedo decir que mi vida profesional ha transcurrido en cercana relación con el trabajo de la organización. Cuando ella se creó hace 35 años fue la garantía de la reconstrucción y la paz mundial. Con ella surgió el germen de una comunidad mundial organizada en la búsqueda de propósitos comunes a todos los hombres, y en efecto, en ella se encarnó no sólo la aspiración a la paz, sino el anhelo de una justicia internacional que comprendía desde el respeto de los derechos humanos hasta la lucha por las reivindicaciones de los pueblos pobres del mundo. Con el paso del tiempo, la organización que surgió en San Francisco se ha encontrado con un mundo distinto y una tarea mucho más compleja. No hay mejor 
homenaje en este día de las Naciones Unidas que dedicar estas reflexiones a avizorar cómo ella debe evolucionar para cumplir con su misión en esta convulsionada sociedad internacional de hoy.

Si se me pregunta cuál es la diferencia más notoria y significativa entre la situación en que ahora es menester gestar la política económica y la que existía en el pasado, sin vacilar respondería que ella es una mayor incertidumbre. Paradójicamente, en esta era de la informática, la agudización de la incertidumbre es un signo de los tiempos y no solamente para la política económica del Ecuador, un país de dimensión económica reducida y, por lo mismo, mucho menos capaz de autonomía en la política económica, sino para todos los países del mundo, aun los más ricos y poderosos. Es claro, sin embargo, que para una nación débil y pequeña, la incertidumbre pesa mucho más sobre la concepción y realización de las políticas.

La incertidumbre tiene naturalmente raíces subjetivas y objetivas. Nuestra "imago mundi" puede haber experimentado tales cambios que ellos nos hagan más conscientes que antes de los efectos de la interdependencia y, por lo mismo, de las fuerzas exogenas que influyen sobre los fenómenos de nuestra sociedad. Esa percepción puede ser calificada como un hecho subjetivo. Lo que sucede, además, es que objetivamente la interdependencia ha crecido en forma radical en los últimos veinte o treinta años por razones económicas y tecnológicas, y la organización de la sociedad internacional se ha quedado rezagada, sin reales medios de acción global que permitan prever y controlar las consecuencias de esa interdependencia. No hay una prueba más clara de esa circunstancia que lo suredido con la energía, cuyo mercado llegó súbitamente al clímax de una crisis, sin que los observadores convencionales hayan anticipado y de algún modo prevenido lo ocurrido. Esa proclividad a la sorpresa que entraña esta interdependencia de nuevo cuño es el principal origen de la incertidumbre.

Pero no es el único. Es también significativo, menos importante quizás, pero significativo, el cambio en la política económica que indujo el dinamismo internacional de los años 60 y que nos llevó a entregarnos a una creciente apertura externa, con todas sus consecuencias económicas, sociales y culturales. Su influencia sobre nuestros países, ya sea como manifestación del capitalismo o como trasunto de un fenómeno de creciente internacionalización de la vida de nuestros grupos dirigentes, ha dado como resultado, sin duda, un mayor dinamismo en los períodos de auge, pero, también sin duda, una mayor vulnerabilidad externa, especialmente peligrosa en los períodos inestables que son los que hemos vivido en los últimos cinco años y que seguramente serán los de la década de los 80 . 
Para los responsables de la política económica es extraordinariamente difícil trabajar con esta incertidumbre. Se necesita tener fe ciega para pensar que hay políticas nacionales que pueden mantenerse con efectividad en medio de las violentas variaciones de circunstancias que siempre tenemos en el mundo de hoy, y hay que ser muy audaz para imaginar que es posible dar con la fórmula que permita compensar oportuna y suficientemente esa inestabilidad. ¿Qué hacer cuando un insensato enfrentamiento entre países petroleros reduce la oferta de petróleo e invierte agudamente una tendencia de precios que se creía predominaría al menos por los próximos seis meses? ¿Qué hacer cuando las alternativas de una campaña electoral en los Estados Unidos son capaces de influir tanto sobre la política monetaria que la tasa "prime" del dinero puede pasar en meses desde el 8 al 18 por ciento y retornar luego al 10 ó 12 casi sin transición? Todo eso habría sido impensable hace diez años. Como esas son hoy las realidades diarias y naturalmente a nadie afectan más que a los países en desarrollo, sin recursos de reserva para imprevistos, sin margen de tolerancia para lo inesperado.

No quisiera que este énfasis en la incertidumbre se atribuyera a un afán de culpar de nuestros males a un insatisfactorio estado del conocimiento. No reacciono contra la incertidumbre como un fenómeno de desconocimiento, lo hago viendo en ella la manifestación de una evolución internacional que ha desatado fuerzas que se escapan cada vez más de las posibilidades de control de la sociedad, y cuyos efectos hemos magnificado los países en desarrollo con los errores de nuestras propias políticas económicas y sociales.

En esas condiciones creo y espero que la característica principal de la Estrategia para la Irr Década para el Desarrollo sea una acción nacional e internacional cada vez más deliberada para usar positivamente de la interdependencia, y reducir así tanto las debilidades $e$ insuficiencias intrínsecas de las políticas nacionales como la incertidumbre en que ellas se debaten.

Basta recordar los problemas más serios que deberán enfrentar en los años 80 los países de América Latina para reconocer que estamos obligados a buscar y encontrar caminos nuevos para transitar por la interdependencia. Por muchas razones, entre las cuales no es la menor el crecimiento vertiginoso de la población, y especialmente de la población activa, todos nuestros países deben realizar esfuerzos enormes de ahorro e inversión y de creación y asimilación de tecnología; todo ello en un medio social tenso, al que es necesario satisfacer en su búsqueda de equidad y en sus afanes de participación. Es como si el "tempo" del devenir humano se hubiese trastornado en una.continua aceleración. El desarrollo de los actuales países industriales se hizo con tasas de crecimiento de la pobla- 
ción que muy rara vez rebasaron el 1 por ciento. Nuestros países tienen que habérselas con poblaciones cuyo aumento frecuentemente excede el 2.5 por ciento y llega en algunos casos a superar el 3 por ciento. La experiencia histórica del desarrollo agrícola muy rara vez registró tasas de aumento de la producción superiores al 2 por ciento, y sin embargo, ahora es casi imposible concebir una expansión equilibrada del producto sin asignar a la agricultura tasas tan altas de crecimiento como el 4 por ciento. Igual tono de urgencia, de necesidad imperiosa de acción, tienen las reivindicaciones sociales en cuanto se rechace la posibilidad misma de la represión como una alternativa.

No es extraño, por lo mismo, que la demanda de medios y de recursos sea tan exigente que los desequilibrios en ella originados alcancen pronto proporciones gigantescas, como es el caso de la deuda externa en cuanto se abrió un cauce nuevo de financiamiento, como es el de la banca comercial internacional.

La tarea que le espera en el próximo futuro a América Latina es, sin duda, difícil por su magnitud y por el entorno incierto en que ella debe llevarse a cabo. El cuadro de Asia y Africa que revela los estudios hechos para la Estrategia de Desarrollo de las Naciones Unidas está lleno de requerimientos, cuya vehemencia apenas se puede concebir si no se está al tanto de las profundas carencias que marcan los cientos de millones de seres humanos que viven en esos continentes, en la pobreza más extrema, tara de la cual tampoco está libre América Latina.

Es un quehacer ingente el que se nos plantea, justamente cuando las secuelas de una interdependencia, cuyos resultados no hemos podido hasta ahora ni prever ni controlar, han invalidado concepciones económicas y han embotado las herramientas de las que se ha servido la política económica, en parte como efecto de esa incertidumbre creciente en que nos debatimos.

Por instinto de conservación los pueblos tienen que reaccionar. Sin un cambio profundo en el orden internacional, las alternativas reales no pueden en el fondo sino acomodarse con más o menos rigor a dos líneas de acción o, si se quiere, dos modelos que describiré simplificadamente en sus formas extremas: el primero buscaría entregarse con las menores rigideces posibles a las exigencias de la interdependencia, y más propiamente de la dependencia cuando se trata de economías subdesarrolladas. Eso significa en el fondo, hacerse tan indiferente como sea posible a la incertidumbre, estado sólo alcanzable en teoría, cuando una sociedad sea absolutamente fluida o móvil, es decir, inestructurada. Ella sería, en ese estado hipotético, parte de una sociedad universal que sólo existe como una entelequia.

La otra tendencia conduce, en su exageración, al extremo opuesto. 
Es el aislarse tanto cuanto sea posible de la interdependencia, esforzándose por eliminar por esa vía la incertidumbre. Es el modelo de la economía cerrada, autárquica, en la medida que cabe una autarquía en un mundo moderno que no puede escapar al alcance cósmico de las limitaciones de recursos y los fenómenos ecológicos. La situación extrema, en ese caso, implicaría una limitación sustancial del ritmo de crecimiento material y de la transformación tecnológica; una sociedad rígidamente estructurada que es, en definitiva, la antinomía de la sociedad universal a la que el primer modelo, por el contrario, se esforzaría por integrarse plenamente.

Pese a estos rasgos de caricatura, creo que no es imposible reconocer en germen direcciones que han tendido a influir en las políticas económicas y sociales de muchos países en desarrollo en los últimos años. Hasta ahora, y éspecialmente en América Latina, es la primera dirección la que parece predominar; más como una adaptación tardía a las fuerzas puestas en movimiento durante el reciente período de auge del comercio internacional y de las economías industriales que como un a respuesta a la interdependencia y a la incertidumbre. En cuanto al segundo modelo o segunda dirección, me arriesgaría a anticipar que si no se pone remedio a la situación actual en la economía internacional, hacia él se encaminarán los grandes países superpoblados de Asia y quizás otros que lo sean menos en distintas latitudes. ¿Acaso no es un síntoma de esa inclinación las reacciones que se advierten en las propias economías industriales, asediadas por las tentaciones del proteccionismo y la renuencia creciente a asumir responsabilidades en la sociedad internacional que ellos trataron de crear desde la revolución industrial?

Este es un escenario, extremo lo confieso, de las direcciones a que puede dirigirse el mundo en esta difícil década de los ochenta.

Intencionalmente no he querido asignar ideologías a estas dos corrientes que pueden emerger de la situación actual. Eso no hace falta, en rigor, para concluir que un mundo con tales contradicciones, sujeto ya sea a tanta inestabilidad o a tantas rigideces, sería incápaz de responder a los anhelos más caros del hombre como un ser social. Muy difícilmente ese mundo podría existir en paz.

En el orden internacional actual está en germen ese escenario extremo de contradicciones y de tensión. Ese orden no es, por supuesto, culpable de toda la infelicidad y la violencia que plagan nuestra era. Pero si no acertamos a reemplazarlo por una organización más satisfactoria de la sociedad internacional interdependiente de que formamos parte, a él nos tendríamos que volver en el futuro para hacerle uno de los responsables principales de la descomposición y el sufrimiento en que nos sumiríamos. Es evidente que esta época de interdependencia 
creciente requiere un ordẹn internacional distinto, que permita no sólo la previsión sino el control humanamente posible de los fenómenos que de ella se derivan. Sin eso no es dable pensar en un mundo sosegado y en paz y en sociedades a la vez justas, dinámicas y con un pleno dominio de su capacidad creadora. Si queremos evitar los extremos que comprometerían in evitablemente la dignidad de los hombres y la personalidad cultural de cada una de nuestras sociedades, hemos de pensar por fuerza en una nueva estructura de las relaciones internacionales. Ella no debe estar al servicio de ningún poder; ha de ser la encarnación de las aspiraciones de una comunidad mundial interdependiente, cuya conducción no podrá nunca concebirse sino como el resultado de la aquiescencia de todos; un control por consenso al que tenemos que acercarnos gradualmente como una condición de la estabilidad, la paz y el progreso.

Suena en verdad utópico. Pero los hechos avanzan más rápidamente que los pronósticos y, lo deseemos o no, hemos comenzado ya a encarar problemas que no pueden manejarse con el viejo orden internacional, sobre todo porque han dejado de ser susceptibles al crudo ejercicio del poder. La energía es el caso más connotado, pero no es el único. Para acercarse a las soluciones se ha ideado ya un sistema llamado de negociaciones globales, que no es otra cosa que el instrumento inicial de esa conducción por consenso a la que antes me referí.

El foro de esas negociaciones globales tendría que ser, por supuesto, las Naciones Unidas. Estas se crearon, como antes dije, en un momento que los grandes países industriales necesitaban reconstruirse y preservar la paz. Su función fue cambiando lentamente hasta convertirse en el ámbito en que el mundo comenzó a conocer en profundidad sus problemas, diferencias y contradicciones. Nos aproximamos a una tercera fase, la más conflictiva y difícil: la conducción global, que es en definitiva la meta que se halla detrás de las resoluciones sobre el nuevo orden internacional. A ese momento se ha llegado luego de años de preparación, en la que han participado tanto los órganos de la sede, como las comisiones económicas regionales y los órganos especializados de las Naciones Unidas. Han pasado ya dos décadas para las cuales se diseñaron estrategias del desarrollo. Algo se ha conseguido con ellas en cuanto a realizaciones efectivas; muy poco en verdad frente a las necesidades; pero la reflexión y la negociación que ellas han provocado son el inmediato antecedente de la situación actual en que el tema es ya ineludiblemente el cambio de estructura de las relaciones internacionales. La Estrategia para la Tercera Década, la -de estos años 80, existe ya en proyecto y es de esperar que se apruebe pronto. En ella se plantean las negociaciones globales como el instrumento apto para comenzar a aproximarse políticamente a las complejidades de la interdependencia. Es 
la tesis que ninguno de los grandes problemas del mundo actual puede ser tratado y negociado aisladamente, ya sea en el ámbito del comercio, el financiamiento, la transferencia tecnológica, la energía, etc. Habria que acercarse a las soluciones simultáneamente para considerar en armonía los intereses de todos y en esa negociación, la estrategia global y las estrategias regionales preparadas por las comisiones económicas regionales, servirían como una pauta para la búsqueda del consenso, en un esfuerzo que sería sin duda el acto internacional de mayor trascendencia del mundo contemporáneo.

No es extraño que todavía no exista acuerdo sobre la agenda y los procedimientos de esa negociación. Quizás ahora sea imposible çonseguirlo $\mathrm{y}$, aun de alcanzarlo, es probable que las negociaciones mismas encuentren obstáculos insalvables. Sería grave que así suceda, pero esa no sería una razón para no insistir en la búsqueda de este camino que para todos se revela como insustituible, aun cuando se quiera no confesar que es así. Hemos comenzado esta década con la conciencia viva de la interdependencia y el sentido de urgencia que emana de la magnitud insólita de los problemas que enfrentan todos los países, y especialmente los del mundo en desarrollo. No hay otra manera de abarcar esos problemas efectivamente y, más temprano que tarde, todos tendrán que rendirse a la evidencia. La evolución de las Naciones Unidas hacia una función de conducción y control global es una necesidad que no puede dejar de percibirse en múltiples esferas de la actividad internacional. Se ha hablado de ella por ejemplo al tratarse de la administración de los fondos marinos y comienza a ser una realidad su presencia y acción en la preservación del medio ambiente. Quedan los campos más conflictivos y tenemos que esperar que en ellos la evolución del sistema internacional se haga rápida y efectivamente, porque de ella depende en buena medida la capacidad para dar respuesta real a los interrogantes sobre el futuro del hombre que enfrenta el mundo moderno. 